\title{
CULTURE DE CHILOMASTIX AULASTOMI
}

\author{
Par LI YUAN-PO
}

Grâce à l'obligeance du Prof. Brumpt, j'ai eu l'occasion d'examiner les protozoaires intestinaux de la sangsue, Aulastomum gulo Moq.Tand, capturée en grand nombre au Bois de Boulogne, à Paris, aux mois de juin et juillet.

Mon expérience montre que presque 100 p. 100 de ces sangsues sont parasitées par des Chilomastix, toujours en coexistence avec Trichomonas sanguisugæ, Entamœha aulastomi et Blastocystis sp. Ces chiffres, indiquent, pour ces trois derniers parasites, une fréquence beaucoup plus grande que celle donnée par Drbohlav il y a quelques années.

Parmi tous les milieux que j'ai essayés, les trois suivants sont les plus favorables pour Chilomastix aulastomi :

1. Milieu de Dorset à $3 \mathrm{gr}$. p. 1.000 de $\mathrm{NaCl}$ recouvert d'eau filtrée.

2. Milieu de Dorset à 3 gr. p. 1.000 de $\mathrm{NaCl}$ recouvert d'un liquide contenant 3 gr. p. 1.000 de $\mathrm{NaCl}$ dans l'eau distillée et des traces d'albumine d'œuf ( 1 et 2 , milieux de Drbohlav).

3. Milieu contenant 1 partie de sérum de cheval et 9 parties d'eau distillée à 3 gr. p. 1.000 de $\mathrm{NaCl}$, chauffé pendant 15 minutes à $100^{\circ} \mathrm{C}$.

Il est facile d'obtenir le contenu intestinal des sangsues contenant les Chilomastix par la méthode du Prof. Brumpt : lavage de la portion rectale au moyen de la fine pipette employée par Drbohlav dans la culture des Trichomonas et amibes parasites du même hôte.

Les Chilomastix se développent particulièrement bien dans les milieux précédents lorsque le $p \mathrm{H}=6,8$ à 7,4 . La température optima est de $20^{\circ} \mathrm{C}$. Les Chilomastix ne se développent pas à $30^{\circ} \mathrm{C}$.; ils meurent en quelques minutes à $37^{\circ} \mathrm{C}$. ; mais ils résistent bien au froid. J'ai pu les conserver pendant une dizaine de jours dans la glacière. A cette température, les flagellés sont encore très actifs et les bactéries associées sont peu importantes. En somme, il me semble que les Chilomastix se développent dans les mêmes conditions de milieu que les amibes et les Trichomonas. Cependant ils paraissent plus sensibles que les Trichomonas et plus résistants

Annales de Parasitologie, $T$. VII, $\mathrm{N}^{\circ} 1 .-1^{\text {er }}$ janvier 1929, p. 61-63. 
que les amibes. Par conséquent, on peut séparer les Chilomastix et les Trichomonas des amibes en attendant la mort de ces dernières (Drbohlav); ou bien, comme les amibes ne se trouvent qu'au fond du tube, en absorbant le liquide à un centimètre au-dessus du fond, à l'endroit où se trouvent aussi un grand nombre de ces deux flagellés. Quand il s'agit des Blastocystis, on peut aussi employer cette dernière méthode ou ajoutẹ de la dextrine dans le

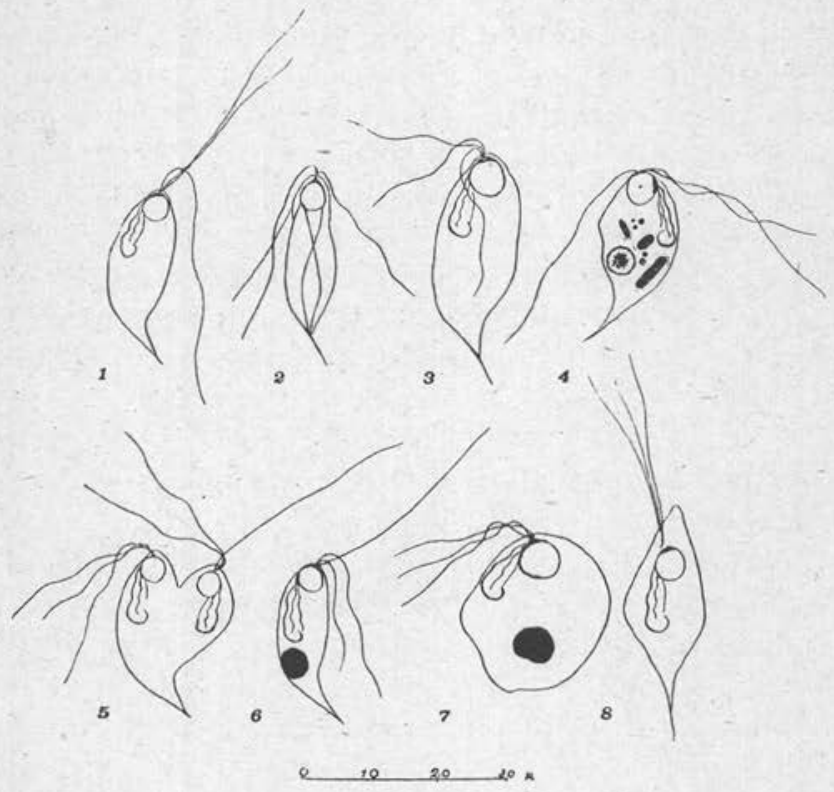

Fic. - 1, forme libre dans l'intestin de la sangsue; 2, forme libre montrant un mouvement rapide; $3,4,5,6,7,8$, formes de culture ; 4 , renferme une levure et d'autres microbes; 5 , forme en voie de division longitudinale ; 6 , et 7 , renferment un grain d'amidon.

milieu (Drbohlav). Je n'ai pu trouver aucun moyen qui permette d'isoler les Chilomastix des Trichomonas. Dans le milieu du sérum de cheval, les Chilomastix peuvent vivre de 10 à 12 jours et dans les deux autres milieux 6 à 7 jours. La souche en est à sa dixième génération et a été gardée pendant environ 2 mois.

Dans la culture, on peut observer, rarement il est vrai, des formes en voie de division longitudinale et quelquefois des éléments très grands, mais jamais l'enkystement.

J'ai observé un fait curieux. Si l'on ajoute dans la culture des globules rouges d'un animal de laboratoire quelconque, comme la 
souris, on voit que ces globules sont rapidement phagocytés par les Trichomonas et les amibes, mais pas par les Chilomastix. Les examens entre lame et lamelle répétés et les frotis de cultures colorés par la méthode de l'hématoxyline ferrique ont été maintes fois pratiqués, mais je n'ai jamais pu trouver de phagocytose des globules rouges chez les Chilomastix, bien qu'ils ingèrent la poudre d'amidon dans les mêmes conditions que les Trichomonas et les amibes.

Le pouvoir hématophage des protozoaires intestinaux a un grand intérêt à cause du rôle pathogène de ces parasites. Par exemple, Entamœba dysenterix et $E$. coli se différencient essentiellement par ce caractère. J'espère qu'on établira si ce même caractère biologique existe aussi chez Chilomastix mesnili, parasite de l'homme, qui présente un grand intérêt dans la pathologie humaine.

Je tiens à témoigner mes sincères remerciements au Prof. Brumpt et au $\mathrm{D}^{\mathrm{r}}$ Langeron, chef de laboratoire, qui m'ont aimablement aidé dans mes recherches.

\section{BiBLIOGRAPHIE}

Belar (K.). - Protozoenstudien, III. Archiv für. Protistenkunde, XLIII, 1921, p. 439-446.

Drвohlav (J.-J.). - Culture d'Entamœba aulastomi Noeller, 1921. Ann. de Parasit., III, 1925, p. 367-368.

- Culture de Trichomonas sanguisuga Alexieff, 1911. Tbid., 1925. p. 369.

Laboratoire de Parasitologie de la Faculté de Médecine de Paris. 